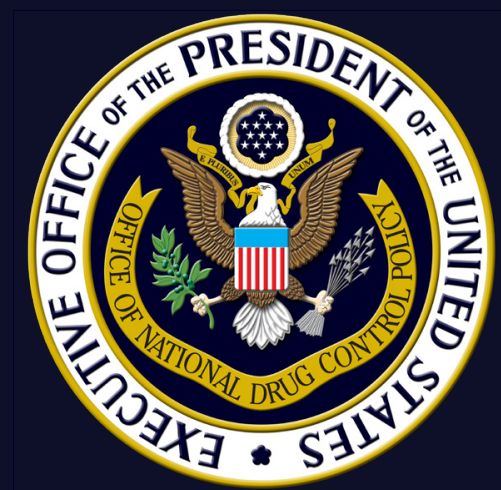

\title{
NATIONAL \\ Drug Control STRATEGY
}

\author{
A Report by the \\ Office of National Drug Control Policy
}




\section{TABLE OF CONTENTS}

Preface

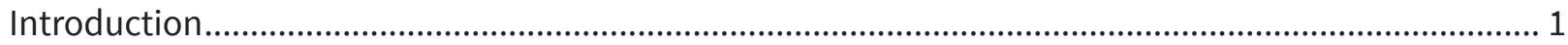

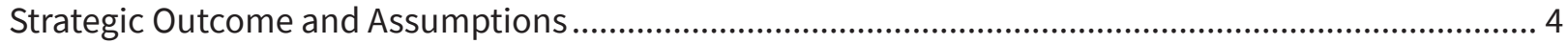

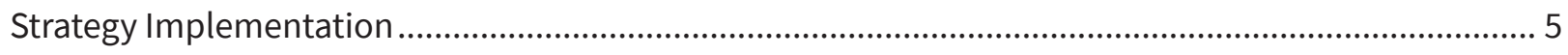

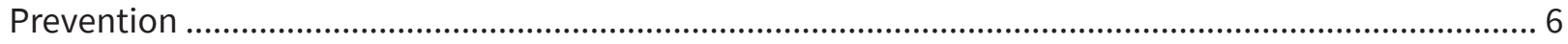

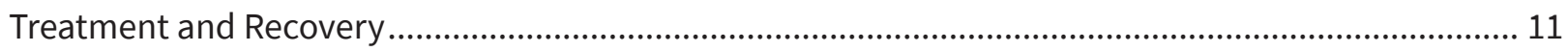

Reducing the Availability of Illicit Drugs in the United States ........................................................... 17

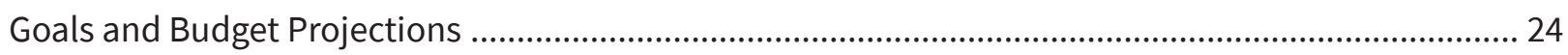

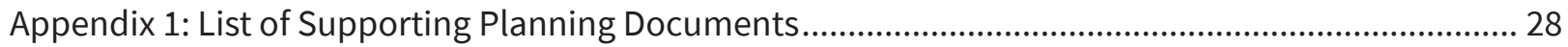

Appendix 2: ONDCP's Role in Facilitating the Achievement of the Strategic Goals and the Existing Coordination Mechanisms Necessary for Achieving the Strategic Goals ........................... 29

Appendix 3: Mission Statement and List of National Drug Control Program Agencies and Role in Achieving Strategic Goals ................................................................................................. 31

Appendix 4: Role of Key Stakeholders and Partners in the Strategy ................................................. 33

Appendix 5: National Drug Control Strategy Research and Data Collection Plan ................................. 37 


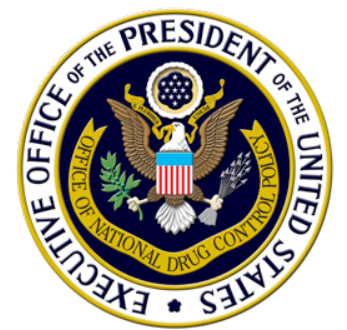

Despite the challenges communities continue to face related to the negative consequences of the trafficking and use of illicit drugs and the continued availability of illicit drugs across the Nation, over the past year we have seen significant progress in strengthening communities across the Nation to address this evolving crisis. The Trump Administration remains focused on making continued progress in its second National Drug Control Strategy dedicated to reversing the adverse impacts of addiction so we may continue to save American lives and set our Nation on a path to being stronger, healthier, and drugfree.

This Strategy focuses Federal government efforts along three complementary lines of effort. First, we must continue to prevent initiates to drug use through education and evidence-based prevention programs. Second, we must continue to reduce barriers to treatment services so that access to long-term recovery is available for those suffering from substance use disorder. And finally, we must continue our work to drastically reduce the availability of these drugs in the United States through law enforcement and cooperation with international partners to eliminate the negative effects that drug trafficking has on the safety of our communities and the well-being of our citizens.

Drug misuse and abuse continues to endanger too many communities, ruin too many families, and takes the lives of too many of our fellow Americans. Drug addiction is causing rises in the number of children in foster care, job insecurity, and transportation safety issues. While this Strategy reflects the President's top priority to address the current opioid crisis and reduce the number of Americans dying from these dangerous drugs, it also sets us on the path to develop further the capability, knowledge, and infrastructure to respond quickly to the evolving nature of our Nation's drug threats. It reflects our understanding of the complex interplay between the availability of drugs in the U.S. market and their use, anticipates changes in the drug environment in both the public health and law enforcement domains, and allows us to adapt our actions and make lasting progress against this historic national security, law enforcement, and public health challenge.

Most importantly, it demands our full effort and a relentless focus on delivering results. The American People should expect nothing less.

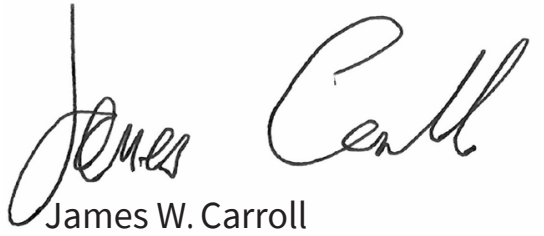

Director of National Drug Control Policy 


\begin{abstract}
"Our Administration remains committed to protecting American families and communities from the dangers of substance use. Working together we will lead our Nation to become a stronger, healthier, and drug-free society."
\end{abstract}

\author{
-PRESIDENT DONALD J. TRUMP
}

\title{
INTRODUCTION
}

During the past year we have indeed made some progress in preventing drug use, reducing barriers to treatment leading to long-term recovery, and reducing the availability of drugs in our communities and our homes. The Trump Administration has made life-saving gains through the synchronized approach laid out in the final report of The President's Commission on Combating Drug Addiction and Opioid Abuse in 2017, President Trump's Initiative to Stop Opioid Abuse and Reduce Drug Supply and Demand in 2018, and the Administration's 2019 National Drug Control Strategy. Nevertheless, far too many Americans continue to lose their lives to drug use, and drugs remain all too available throughout our Nation. While some advances have been made in our daily work to address the country's unprecedented drug crisis, we remain far from achieving the President's vision of being a healthier and drug-free society.

We must continue the hard work of individuals and organizations at all levels of government and civil society in an effort to resolve the crisis and to save American lives. It is well-understood that the crisis has evolved over several decades and has steadily worsened with time. Every state and county, and every socioeconomic group in our country, continues to be affected by the negative consequences of illicit drug use. However, as in the past year, our long-term success can only be achieved by our collective commitment to save lives and establish lasting solutions to this historic problem. The partnership of our law enforcement and public health professionals, working side-by-side, and inspired by the strength and wisdom of families who have lost loved ones to the scourge of drug use, continue to make a significant difference. This National Drug Control Strategy, the Trump Administration's second, affirms the President's priorities for addressing the challenge of drug trafficking and use, now and in coming years. It also provides the strategic direction necessary for the Federal government to prevent initiates to drug use through education and evidence-based prevention, provide treatment for those suffering from the disease of addiction so they can reach long-term recovery, and reduce the availability of these dangerous drugs in every American community.

The President's top priority remains, as he articulated in his first strategy, to address, head on, the current opioid crisis and reduce the number of Americans dying from these dangerous drugs. In 2017, there were more than 70,200 drug overdose deaths in the United States. ${ }^{1}$ More than 47,500 of these deaths involved an opioid, and more than half of these deaths involved a synthetic opioid such as illicit fentanyl or one of its analogues. From 2014 to 2017, the number of deaths attributed to synthetic

${ }^{1}$ These are the latest available statistics of annual mortality due to drug overdoses in the United States. The 2018 statistics are expected to be issued by the Center for Disease Control and Prevention (CDC) in early 2020. 
opioids like fentanyl and its analogues increased 413 percent, and these synthetic opioids are now involved in more deaths than any other drug such as prescription opioids, heroin, or cocaine. The infectious disease consequences of the opioid epidemic is also of grave concern. Since 2010, the United States has seen hepatitis $C$ infection increase more than three-fold. Progress made in HIV resulting from injection drug use has stalled. Moreover, methamphetamine availability and use shows signs of renewed growth. According to the most recent available data, 10,333 Americans died in 2017 from a drug overdose involving methamphetamine and other psychostimulants with abuse potential, and half of these deaths also involved a prescription or illicit opioid, with a quarter involving a synthetic opioid such as fentanyl.

As he has since the beginning of his Administration, the President has marshalled every available resource throughout the Federal government to address America's crisis of drug abuse and addiction ${ }^{2}$, requesting over $\$ 34.6$ billion in his Fiscal Year 2020 Drug Control Budget to help states, communities, and law enforcement respond to the drug crisis and curb drug trafficking through several existing and new initiatives. The Trump Administration's whole-of-government approach reflected in these resources and articulated in this Strategy is focused on achieving a singular and overarching purpose: to prevent Americans from dying of a drug overdose.

While confronting today's drug crisis to arrest its growth and reduce its effects, we must also redouble our efforts to develop the capability, knowledge, and infrastructure to respond to the evolving nature of the drug threat. Over the past year we have seen the drug crisis transform in every dimension. A much larger variety of new and highly potent synthetic opioids and other synthetic drugs are being rapidly developed and shipped into the United States at an increasing rate. New marketing and sales techniques are making their detection and interdiction more challenging than ever. The historically low price for some synthetic drugs like methamphetamine is putting them within the economic reach of even more potential users, leading to an increasing trend of polydrug use across America. We have even seen an evolution in the manner in which drugs are taken into the body, including a startling and dangerous increase in concentrated marijuana-type drugs being ingested through vaping devices.

We must also confront the increasing availability and use of cocaine in the United States. The cultivation of coca and production of cocaine in Colombia, the source of the vast majority of the cocaine in the U.S. market, remains at record highs even in light of a slight leveling in 2018. Cocaine use in the United States continues to rise again after many years of decline. The National Survey of Drug Use and Health (NSDUH) shows that in 2018 there were 1.9 million people aged 12 and above who were past-month users of cocaine and 874,000 new cocaine initiates, averaging approximately 2,400 individuals per day. Moreover, the suspension of aerial eradication programs in Colombia that began in 2015 led to even greater yield from coca plants, resulting in increased production and purity levels that continues to bring negative consequences. From 2016 to 2017, overdose deaths in which cocaine was the primary

${ }^{2}$ The Diagnostic and Statistical Manual of Mental Disorders (DSM-5) contains descriptions and symptoms of all medical disorders classified by the American Psychiatric Association, including substance use disorder. The Strategy and ONDCP uses the word "addiction" to describe compulsive drug seeking despite negative consequences. ONDCP's use of the term addiction is consistent with the DSM definition of substance use disorder but acknowledges that addiction is not a specific diagnosis in the DSM-5. 
contributing drug increased 34 percent.

The fundamental motivation of drug traffickers remains unchanged. They continue to attempt to secure ever-greater profits by expanding their customer base through the introduction of novel substances that create new user experiences, reducing production overhead, and mitigating risks to their supply chains by continually finding new methods of concealment and routes into the United States. The exponential growth in the availability and use of synthetic drugs in the United States continues to show us the face of drug use and trafficking for the foreseeable future. Drug trafficking organizations can avoid the costly process of harvesting illicit crops and producing plant-based drugs by the much cheaper and faster process of chemical synthesis. Potent synthetic drugs are smuggled across our borders in small quantities that can be more easily concealed than bulkier plant-based drugs. They are also purchased cheaply on the dark web using cryptocurrencies that provide anonymity, and shipped into the United States through international mail or as express consignment shipments. The combination of low production cost, the anonymity of the dark web and cryptocurrencies, and drugs with higher potency than their plant-based counterparts creates a favorable risk-reward structure that drug traffickers are now embracing to an even greater degree than ever before.

Given the current drug crisis facing America, and the President's priorities, this Strategy continues its strong bias toward action. The three lines of effort and associated nine goals contained in the Strategy were determined by drawing upon the collective expertise at the Federal, State, local and Tribal levels by key stakeholders in the governmental, academic, civic, law enforcement, and public health communities. Their deep understanding of America's drug crisis was fundamental to determining the Strategy's nine goals and has allowed us to better understand the complex interplay between the availability of drugs in the U.S. market and their use, anticipating changes in the drug environment in both the public health and law enforcement domains, and adapting our actions to seize the initiative to make lasting progress against this historic challenge. Specifically, Goals 1, 2, 4, 5, and 6, which are associated with the line of effort to prevent initiates to drug use, were selected based on our consultations with public health experts whose research and clinical experience determined that addiction is a disease that must be prevented from the start, and prevention is most effective when it is carried out over the long-term with repeated evidenced-based interventions. Similarly, Goals 1 and 3, which relate to the treatment and recovery line of effort, were selected based on our consultations with public health experts who understand that addiction is a chronic disease that should be treated like any other medical condition. This evidence, based on research and clinical expertise of our stakeholders, informed our decision to establish these goals. Finally, those goals related to addressing the availability of illicit drugs, Goals 1, 7, 8, and 9 were the result of consultations with Federal, State and local and Tribal government and law enforcement organizations. These consultations clearly demonstrated that almost all illicit drugs are produced outside the United States and then trafficked across the borders or via international mail or express consignment carriers. This evidence informed our selection of the goals that will aggressively reduce the availability of illicit drugs in American communities.

The global drug trafficking environment is vast, dynamic, and adaptable, but it is not without 
vulnerabilities. It is only through a unified effort in which the Federal government works with, and in support of, creative and resourceful individuals and organizations across the country and within the nations of our international partners, that we can address this complex national security, law enforcement, and public health problem.

\section{STRATEGIC OUTCOME AND ASSUMPTIONS}

This Strategy focuses on achieving one overarching strategic outcome:

Building a stronger, healthier, drug-free society today and in the years to come by drastically reducing the number of Americans losing their lives to drug addiction in today's crisis, and preparing now to dominate the drug environment of the future. This will be done by preventing initiates to drug use, providing treatment services leading to long-term recovery for those suffering from addiction, and aggressively reducing the availability of illicit drugs in America's communities.

This Strategy consists of three interconnected lines of effort designed to achieve the President's strategic outcome of building and fostering a stronger, healthier, and drug-free society: prevention; treatment and recovery; and reducing the availability of drugs in America. The single and most important criterion of success is saving American lives, and achieving that outcome requires the Federal government to work with partners at the State, local, and Tribal levels; the healthcare sector; industry; foreign partners; and every concerned American citizen to advance our Nation's efforts to promote and maintain healthy lifestyles, and help build and grow safe communities free from the scourge of drug use and addiction.

This Strategy makes several key assumptions:

- Deliberate, sustained, and well-coordinated evidence-based prevention and education efforts will, over time, reduce the number of Americans who initiate illicit drug use.

- Better prescribing practices and the promotion of alternatives to prescription drugs that hold a high potential for addiction and misuse will have a positive effect on reducing the number of initiates to illicit drug use.

- Increasing the availability, access, and quality of evidence-based treatment and recovery services for substance use disorder, particularly in rural, tribal and other underserved communities, will lead to a greater number of Americans achieving sustained recovery.

- $\quad$ Reducing the availability of illicit drugs in the United States by disrupting the illicit drug supply chain will relieve pressure on our public health efforts, allowing our historic effort to prevent drug use and increase the availability of treatment to take hold, and increasing the potential sustainable success over time.

- Aggressive and versatile drug trafficking organizations will respond to sustained pressure 
placed upon them by disruption, dismantlement, interdiction efforts, and judicial/ prosecutorial efforts, and will adapt their production and trafficking methods to minimize risk and maximize profit.

This Strategy acknowledges several key challenges:

- Drug trafficking and transnational criminal organizations are highly adaptable.

- The path to substance use disorder is multifaceted and extremely individualized. Consequently, prevention, treatment, and recovery support services must also be multifaceted and individualized to maximize effectiveness.

- Synthetic drugs are easily modified, and rapid modifications in synthetic drug types and structures make their early detection a challenge.

\section{STRATEGY IMPLEMENTATION}

The three fundamental lines of effort that form the heart of this Strategy-prevention, treatment and recovery, and reducing availability-are complementary and mutually supporting. Reducing the size of the illicit drug using population involves preventing initiates to illicit drug use through education and evidence-based prevention programs. Providing effective treatment services leading to long-term recovery for those suffering from substance use disorder, often using medication-assisted treatment (MAT) combined with therapy, moves people out of the active user population and puts them on the path to recovery. By reducing the number of individuals who use illicit drugs through prevention and treatment, we can diminish the market forces pulling illicit drugs across our borders and into our communities. Simultaneously, we must drastically reduce the availability of these drugs in the United States. Increased availability expands the opportunity for individuals to initiate drug use, and the path from first use to chronic use can be brutally short, particularly for potent and highly addictive drugs like methamphetamine and opioids. By reducing availability we not only lessen the negative ancillary effects of drug trafficking that impact the safety of our communities and the well-being of our citizens, we also relieve the pressure on the public health domain in its prevention and treatment efforts.

This Strategy does not enumerate every activity that the Federal government and key stakeholders must execute in order to achieve the President's strategic outcome. Rather, it articulates the President's drug control priorities and sets the strategic direction for the Administration to prevent Americans, especially our future generations, from falling into the cycle of drug use and addiction; to provide Americans who suffer from substance use disorders with world class treatment and recovery services; and to protect America's citizens from the negative effects of drug trafficking and use. It also provides Federal drug control departments and agencies the strategic guidance they need to develop their own drug control plans and strategies and ensures programming and resource decisions about Federal drug control budget dollars are allocated in a manner consistent with the Administration's priorities. 


\section{PREVENTION}

Preventing drug use before it starts is a fundamental tenet of a comprehensive approach to drug control. The science of prevention has evolved and significantly improved, and decades of research show that prevention is most effective when it is carried out over the long-term with repeated evidence-based interventions. Early detection of those most at risk united with education programs and community support mechanisms can alter the trajectory of young people's lives by increasing protective factors while reducing risk factors. Studies show that addiction is a disease that can be prevented and treated through sound public health interventions.

Early recognition and addressing risky substance use can help interrupt the trajectory toward more chronic substance use disorders and opportunities to screen for risky behavior should be widespread. Many medical organizations have developed evidence-based screening tools and recommend screening for drug use and prescription drug misuse for adolescents, as well as adults. All health systems should be using screening tools as part of routine health care. Given the high prevalence of co-occurring mental and substance use disorders, we must ensure adoption of comprehensive screening and integrated treatment for both. There is a significant relationship between mental health and substance use disorders at all ages, and it is common for persons to use substances in an attempt to self-medicate the symptoms of mental illness. Substance use can mask or exacerbate symptoms of mental illness and both disorders share common risk and protective factors that should be assessed and addressed together where possible, and treated when indicated. Facilities and professionals serving persons with either disorder should have the skill and operational capacity to provide integrated treatment that addresses behavioral and physical health, family, and environmental problems in addition to substance use. Additionally, treatment providers should recognize the different prevention and treatment considerations for children and young adults, and provide age appropriate care. Because the developing brain continues growth until at least age 25 , children and young adults are more susceptible to addiction. Children and young adults also require age appropriate and relevant substance use prevention which integrates elements of sociocultural environment, social norms, trauma informed approaches, and resiliency-building interventions to help them make healthy lifestyle choices.

Individuals who have experienced a high number of traumatic or challenging experiences in childhood are at a significantly elevated risk for developing substance use disorder, and therefore need increased access to prevention education and intervention. Adverse Childhood Experiences (ACEs) describes the exposure of a person under the age of 18 to trauma, abuse, household challenges and neglect. As the number of ACEs increases, the likelihood of engaging in risky health behaviors including alcohol and drug use also increases. Research from the National Center for Chronic Disease Prevention and Health Promotion has shown that there is a correlation between having a higher ACE score and the number of prescriptions or classes of illicit drugs used by an individual, even long after the initial exposure to the childhood trauma. While significant challenges early in life, and a high ACE score, do not determine that a child will have poor life outcomes, they nonetheless present an increased need for protective factors to prevent drug misuse. Young people who are identified as being particularly vulnerable to 
addiction have an increased potential for positive outcomes if they have access to supportive adults, exposure to evaluated drug prevention education, opportunities for academic and extracurricular engagement, and clear boundaries related to conduct and drug use.

Evidence continues to demonstrate that combining multiple evidence-based approaches in a comprehensive prevention program is more effective than a single activity alone. Moreover, these early investments pay large dividends in substantially reducing treatment and criminal justice costs, saving taxpayer dollars while reducing the number of young people whose lives are tragically affected by early substance misuse.

Finally, while the opioid crisis in America has mobilized awareness, action, and resources to reduce overdose fatalities, we cannot ignore the larger landscape of substance use and substance use disorders. Poly-substance use has become much more common as individuals make economic decisions about the drugs they use. It is important that we take the opportunity to leverage the momentum of our national response to the opioid crisis, and apply it to preventing the first use of all drugs using the decades of scientific evidence on effective primary prevention to launch and fully support effective prevention in homes, schools, the workplace, and communities.

\section{Strengthening the Capacity of State, Local, and Tribal Communities to Identify and Prevent Substance Misuse}

Family, friends, and local communities are the first line of defense in preventing substance use and misuse. In addition, positive adult involvement in children's lives reduces the likelihood of drug use. Given the strong relationship between excessive alcohol use and binge drinking, and the misuse of prescription opioids and other illicit drugs, this Strategy emphasizes the need to implement effective community-based strategies to reduce misuse of legal substances, along with those to reduce the initiation of illicit drug use. Parents and primary caregivers must understand that they can make the most significant difference in the child's attitudes and values regarding the use of drugs. Religious and faith-based organizations are also an integral part of the community response to substance misuse, and clergy and faith-based organizations have been critical allies at keeping youth away from drugs and providing successful support when youth have turned to drug use. This Strategy supports and reinforces the positive resources that family, friends, and the community can bring to bear on this crisis at both the prevention and the treatment and recovery levels. Parents and families are historically under-represented in prevention programs despite the fact that family-based programs play a vital role in delaying the onset and use of alcohol and other drugs. This is true for school outreach programs as well. Finally, to build effective grassroots solutions, local leaders need greater access to data about drug use and drug-related deaths in their communities, as well as information on the demographic factors that may be driving those trends. Our rural communities have a particular need for comprehensive information about the many Federal funding resources available to combat addiction and to build capacity to assist a community in responding to the crisis. Federal grant-making agencies should continue to assist these rural communities in knowing what to apply for and the process for applying for these resources. 


\section{Enhancing Research and the Development of Evidence-Based Prevention Programs}

The National Academies of Sciences, Engineering, and Medicine outline three categories of prevention intervention: universal, selective, and indicated. Advancing our ability to prevent drug use before it starts will require, among other things, more widespread adoption and use of evidence-based methods to identify at-risk individuals using strategies that allow for screening, brief intervention, and referral to treatment. This is especially important for adolescents and young adults, from the middle school years through college age. In addition, we must work with stakeholders to increase opportunities to educate and inform child welfare professionals and healthcare providers about the early signs of substance misuse and identify resources to support pregnant and parenting women, children of parents with substance use disorders or addiction, and children born with neonatal abstinence syndrome (NAS). We must engage the research sector and prevention community to build evidence on interventions that address the Nation's ever-changing addiction crisis in diverse communities and conditions.

\section{Continuing to Strengthen ONDCP's Drug Free Communities Support Program}

The Office of National Drug Control Policy's (ONDCP's) Drug-Free Communities (DFC) Support Program, created by the Drug-Free Communities Act of 1997, undergirds the Administration's focus on preventing and reducing youth substance use at the community level. The DFC Program provides grants to community coalitions to strengthen the infrastructure among local partners to create and sustain a reduction in local youth substance use. Since the DFC Program's inception, findings from evaluations of the DFC Program demonstrate that DFC-funded community coalitions have reduced youth substance use. According to the DFC's 2018 National Cross-Site Evaluation Report, on average DFC-funded communities saw significant reductions in middle school and high school aged youth. For example, past 30-day alcohol use decreased by 19 percent, past 30-day tobacco use decreased by 31 percent, past 30-day marijuana use decreased by 7 percent, and past 30-day prescription drug use decreased by 24 percent among high school students in DFC-funded communities. The DFC Program, through the National Coalition Institute $(\mathrm{NCl})$, will provide training to ensure DFC-funded community coalitions have the resources, tools and skillset they need to develop, strengthen, and sustain the prevention infrastructure within their communities and among their local partners to effectively prevent and reduce youth alcohol, tobacco, marijuana, vaping, and prescription drug misuse.

\section{Addressing Safe Prescribing Practices}

Safe prescribing practices are essential in primary prevention by decreasing the risk of drug addiction in patients who take opioids and controlled medications. Safe prescribing is also important for patients using medications at high dosages or with central nervous system depressants that in combination can lead to drug interactions, including overdose. Finally, safe prescribing also includes prevention of using medications for non-medical purposes.

Significant effort has gone into the development of evidence-based guidelines for the use of 
medications and non-pharmacological therapies for the treatment of acute or chronic pain. These guidelines include recommendations for the dosing and duration of use of opioid analgesics, the use of lower risk opioid and non-opioid medications, and the development of innovative pain therapies that avoid potentially addictive medications. Another key area of concern is the practice of coprescribing opioids and benzodiazepines or other drugs that increase the risk of opioid overdose or fatal respiratory depression. Overdose data shows that more than 30 percent of overdoses involving opioids also involve benzodiazepines. While opioid and other controlled substance prescribing practices continue to improve, continued monitoring, evaluation, and improvement, along with the enhanced ability to track prescribing across providers and states through the integration of Prescription Drug Monitoring Programs (PDMPs) and Electronic Health Records (EHRs) are essential to promoting safe and responsible prescribing, while also assuring appropriate pain care.

Prescribing naloxone can be life saving for patients on high dose opioids, along with those who use illicit drugs or are otherwise at risk for an accidental overdose. In 2018, the CDC reported that only one naloxone prescription was dispensed for every 69 high-dose opioid prescriptions, despite the fact that the number of naloxone prescriptions has doubled from 2017 to 2018. In 2017, unintentional overdoses involving prescribed medications other than illicit fentanyl were more than twice as common as in 1999. The medical community has responded by limiting opioid prescriptions both in terms of the total number of pills prescribed and the total morphine milligram equivalent (MME) of the prescriptions dispensed. The total year-to-date billions of MMEs dispensed as of September 2018 decreased 16 percent over the prior year.

While we have made significant gains in reducing cases of unsafe or inappropriate prescribing, we must remain aware that patients with acute and especially chronic pain and who rely upon opioid medications to live comfortable and productive lives legitimately require access to opioid medications. Moreover, providers who know and understand their patients are in the best position to administer opioid medications at the correct dosage in a safe and responsible manner. Some patients do require long term pain management that includes opioids and others may be able to work with their clinicians to appropriately taper or discontinue opioid medications. Patients may also require ongoing treatment for any co-occurring behavioral health conditions such as depression. In some cases, specialty referral to a pain management or substance use disorder specialist may be necessary. While treatment guidelines are important and beneficial, the doctor-patient relationship is the foundation of quality medical care and must be tailored to meet the individual patient's needs.

\section{Expanding the Use of Prescription Drug Monitoring Programs}

A PDMP is a proven means to increase accountability in opioid prescribing practices by providing information that allows for the coordination of multiple medications, as well as to prevent adverse drug interactions. However, PDMP use faces challenges nationwide. In some states PDMP checking is optional, and many providers report difficulty using their PDMP because it is not integrated with EHRs which interrupts providers' workflow and creates practical barriers to their use. In those cases where states' integration services are available, the service can be costly. Providers also cite a lack 
of interstate data-sharing and concerns about patient confidentiality as reasons not to fully use the PDMP. Currently, two PDMP data sharing hubs exist and many states share data freely across state lines. However, remaining technical, legal, and procedural barriers remain and have thus far prevented the full development and execution of a nationwide PDMP capability. Expanding the use of PDMPs is a fundamental element of the President's Initiative to Stop Opioid Abuse, our Strategy, and ensuring the safe, legal, and responsible prescribing of opioids for those who need them. Expanding the use of PDMPs across the country means each state is choosing the system(s) it wants based on cost, needs, or whatever else they determine are important factors; ensuring that all systems communicate with each other and are integrated within provider workflows so they can be useful to providers; and the creation of a federated group of state PDMPs all able to seamlessly share data needed to connect with one another across the country. We will continue to work with our key stakeholders to build on existing research regarding barriers to nation-wide PDMP implementation, and drive PDMP integration and data sharing, including efforts that address any legal and interoperability challenges. We will also pursue incentives for states to make checking PDMPs mandatory for all providers, such as the Centers for Medicare and Medicaid Services' new incentive that offers five bonus points to prescribers who query the PDMP under the Medicare Merit Based Incentive Payment System.

\section{Expanding Drug Take-Back across the Country}

The Drug Enforcement Administration's (DEA) twice-yearly Take-Back Day serves as an opportunity for citizens to dispose of unused and unneeded prescription drugs and a chance to support community drug prevention efforts. This past year, amidst an outbreak of vaping-related lung illness, the DEA has included the Take-Back of vaping products in addition to unused prescriptions for the first time. Although year-round take-back programs are expanding, including some by retail drug stores, the DEA program remains an important element to raise public awareness about the need to reduce unused medications available for potential diversion and misuse. Expanding the number of registered collectors, including hospitals and law enforcement centers, would allow states and municipalities to reduce their reliance on the Federal government for collection, disposal, and transportation. It should be noted that the number of authorized collectors has climbed from almost 6,000 in January 2019 to over 8,850 in December 2019, an increase of 40 percent. The DEA and other Federal partners should work to engage State, local, and Tribal governments to raise awareness of the importance of disposing unused medications, expand the number of permanent disposal sites across the country, and increase the opportunity for their citizens to do so safely and easily. In addition, at-home disposal options should be more widely available, particularly in rural and tribal communities where prescribing rates are historically high, take-back options are limited, and transportation may be a barrier to accessing existing disposal locations.

\section{Conclusion}

Decades of research and data demonstrate addiction is a preventable disease. Today, we continue to face a compelling need to invest in a comprehensive approach to preventing drug misuse that emphasizes concrete and lasting policy change at the Federal, State, Tribal, and community levels. 
The Administration will continue to focus its efforts and work across the government to empower communities, youth, parents, caregivers, and families to come together to create sustainable programs, policies, and practices to combat drug abuse. We know that every dollar we invest in evidence-based substance use prevention programs has the potential to save much more in health care and criminal justice system costs and enhance the overall quality of life for communities and their citizens.

\section{TREATMENT AND RECOVERY}

Addiction is a chronic medical condition that affects the brain by causing distinct cognitive, behavioral, and physiological changes. There is a need to improve the availability of treatment while concurrently enhancing the quality of that treatment. Research shows that treatment is most effective when it addresses addiction as a chronic condition requiring continuing services and support structures over an extended period of time. This can include ongoing outpatient services including MAT programs, intensive initial services such as detoxification, hospitalizations, and residential treatment, followed by continued care and recovery support in the community. Expanding treatment availability also requires accessibility for older adults and people with disabilities, including ensuring treatment centers are physically accessible. Every individual needs an assessment and individualized treatment plan to address their needs as they relate to opioid and other substance use disorders.

Unfortunately, most people who need treatment do not seek it. According to the NSDUH, in 2018 an estimated 21.2 million Americans aged 12 or older needed treatment for a substance use disorder, but only 3.7 million received any kind of treatment and only 2.4 million received that treatment at a specialty facility - a disparity known as the "treatment gap." In some cases treatment capacity is simply not available, and in others people do not fully acknowledge their need for treatment. Therefore, in addition to expanding treatment capacity, we need to engage with those people who need treatment but, for whatever reason, are not seeking it. Furthermore, according to the 2018 NSDUH, 62 percent of the 7.4 million working age adults who had illicit substance use disorder were employed either fulltime (45 percent) or part-time (17 percent). The perception that one must "hit rock bottom" to need treatment is not accurate, and we must work to raise awareness of early intervention.

As a Nation, we must encourage people who need treatment to seek it, create greater access to treatment, and ensure there is adequate capacity and quality to accommodate the need. The Administration prioritizes several distinct initiatives to achieve these goals. First, we must expand a proactive response to overdoses to ensure that the patient can enter into a treatment program designed to meet his or her individual needs. Second, we need to use evidence-based approaches to treatment and make MAT the standard of care for opioid addiction. This means increasing the number of physicians providing high-quality, evidence-based MAT for opioid use disorders and increasing the availability of MAT for incarcerated individuals and people living in rural and tribal communities. Expanding treatment infrastructure will enable us to increase the initial treatment for the vast majority of people who require treatment but are unable or unwilling to obtain it. Third, we need to ensure that health insurance plans provide substance use disorder benefits in parity with medical/surgical 
benefits and implement the SUPPORT Act which reduces reimbursement barriers, to encourage people who need treatment to make the positive decision to pursue it. Finally, the use of drug courts and diversion programs will foster entrance into treatment programs, steering people away from the cycle of destructive and self-defeating behaviors that is the hallmark of the disease of addiction.

People in long-term recovery demonstrate that recovery is possible and share the message that addiction is a disease and not the result of a personal or family failing. In doing so, they help lift the stigma, misunderstanding, and shame that prevent too many Americans from seeking help for substance use disorders. Often, these factors can close off opportunities for those in recovery who seek to become healthy and fully rejoin and contribute to their communities. Implementation of recoverysupportive and drug-free workplace policies is another important component to improve both the health of individuals and communities, as well as economic outcomes for affected workers. The Administration recognizes the toll that misunderstandings and stigma can take on people, families, and communities struggling with addiction, and is taking steps to address them.

Addressing these and other challenges will require a comprehensive multi-year strategy to educate the public and policymakers, reduce stigma and misunderstanding of addiction, better integrate substance misuse screening and treatment into mainstream health care, build and stabilize the addiction treatment workforce, increase access to treatment, and foster more effective approaches to care for people with substance use disorders.

\section{PROVIDING TREATMENT}

\section{Improving the Response to and Monitoring of Overdose}

Naloxone is an opioid antagonist medication that can rapidly reverse an opioid overdose. However, access to naloxone varies throughout the country. Most states have protocols to expand access to naloxone, such as allowing pharmacists to dispense naloxone under a standing physician's order. The U.S. Food and Drug Administration (FDA) is working to facilitate the development of nonprescription naloxone by creating and testing appropriate consumer-friendly Drug Facts labels. However, even simple rescue breathing can keep a person alive until the naloxone arrives and can be administered. We will begin to increase public awareness of the importance of rescue breathing as a critical life-saving measure in the event of an opioid overdose when naloxone is not immediately available. Moreover, we must do more to ensure that the reversal of a potentially fatal overdose is not just another event in a long and protracted struggle with an addiction to dangerous drugs, but rather the first important step toward effective treatment and sustained recovery.

\section{Enhancing Evidence-Based Addiction Treatment}

Treatment models that demonstrate the best outcomes incorporate behavioral, psychosocial, and pharmacological elements, and are tailored to the specific circumstance of the individual. The ability to provide evidence-based treatment for those who need it depends on skilled and well-trained providers who are appropriately credentialed and licensed. This must include a complete assessment 
for substance use disorders by a qualified medical professional; access to addiction treatment such as MAT as a deliberate choice made by a qualified professional in consultation with the patient for a substance use disorder; access to relevant psychosocial treatments such as therapy and relapse prevention; and, the treatment of co-occurring medical and mental health disorders. We must help health providers reduce and treat incidents of NAS by promoting responsible drug prescribing for pregnant women, promoting uniform screening and diagnostic tools, and providing women and their babies with evidence-backed pre- and postnatal treatment. Health providers and other stakeholders should also promote effective gender-relevant models for substance use disorder treatment for pregnant and parenting women. Children and young adults have unique prevention and treatment considerations, and the treatment gap for youth and young adults ages 12-17 is greater than the general public. We need a concerted effort to engage clinicians, school staff, employers, families, caregivers, juvenile justice professionals, community leaders, and health plans and issuers to ensure youth receive treatment that is developmentally appropriate, readily available, and adequately covered by insurance plans.

\section{Eliminating Barriers to Treatment Availability}

Individuals with substance use disorders, including opioid addiction, should have access to evidencebased treatment. According to the Bureau of Justice Statistics and the Substance Abuse and Mental Health Services Administration (SAMHSA), this is particularly true for people in the criminal justice system where nearly 60 percent of people in state prisons and two-thirds of people in jail met the criteria for drug dependence or misuse. Fewer than half of the privately funded substance use disorder treatment facilities offer MAT, and only a third of patients with opioid use disorders have access to those treatments. This is especially true in rural areas where the compelling need for access to treatment far exceeds its availability. The Administration will work across the Federal government to remove barriers to substance use disorder treatments, including those obstacles to FDA-approved MAT, counseling, certain inpatient/residential treatment, and other treatment modalities. All primary care providers employed by the Federal government should screen for alcohol and drug use disorders and, if the patient requests it, provide substance use treatment or a referral for such treatment.

\section{Leveraging Drug Courts and Diversion Programs}

Providing individuals arrested for non-violent drug-related offenses the opportunity to participate in a drug court program or outpatient treatment while under supervision is increasingly becoming the practice throughout the country. From 2009 to 2014 the number of drug courts in the United States increased by 24 percent, reaching 3,057, and today there are more than 3,100 drug courts across the United States, half of which are adult treatment drug courts according to the Department of Justice. Recently, some pioneering police departments began diverting individuals addicted to drugs directly to treatment in lieu of arrest. Many communities are adopting pre-arrest diversion programs where individuals with a substance use disorder are offered treatment in lieu of arrest and deflection models, where those struggling with addiction can walk into a participating police station 24 hours a day for police-assisted rapid treatment entry. The Administration supports these innovative programs and will 
continue support for State, Tribal, and local drug courts to provide offenders struggling with addiction access to evidence-based treatment as an alternative to or in conjunction with incarceration, or as a condition of supervised release.

\section{Building the Addiction Treatment Workforce}

Additional efforts must be made to build an addiction medicine infrastructure and expand the addiction profession and peer recovery support services workforces. Medical providers and patients may not have access to a network of treatment and recovery providers and services, and the actual availability of services when needed continues to be a challenge. Federal partners, medical institutions and educational systems must improve recruitment efforts to build and broaden addiction medicine expertise. The entire medical community is encouraged to engage in expanding addiction medicine knowledge. The current climate requires expansion of addiction medicine specialists in psychiatry and general medicine. Beyond the addiction medicine experts, all medical specialists are encouraged to learn about the treatment of addiction. The addiction treatment workforce covers a broad spectrum of professionals from peer counselors and peer support specialists, to addiction counselors, social workers, nurses, nurse providers, physician assistants, psychiatrists, and physicians of all specialties. We will work to grow and enhance all levels of the professional, mid-level and paraprofessional addiction workforces.

\section{Improving Efficiency in Surveillance and Infrastructure}

Current public health infrastructure and its monitoring systems must improve to enable real-time information and epidemiological surveillance. Efforts must be made to understand infrastructure and monitoring capabilities to improve existing systems. Modernizing public health data systems includes having a trained workforce that can manage modernized systems and develop and improve the criteria and indicators necessary for identifying new or evolving classes of illicit drugs. A part of this process is to examine the capabilities and capacities around local toxicology testing, including the recommended minimum detection levels for screening and confirmatory testing of drugs, the role of coroners and medical examiners, and how issues with infrastructure impact data collection. The Federal government, in collaboration with States and localities, should explore ways to better measure and track treatment services and recovery housing availability against demand and need on the local, state, and national levels.

\section{SUPPORTING RECOVERY}

\section{Utilizing Recovery Support Organizations}

The sense of community and the establishment of a safe place to live are essential ingredients for all people who are breaking the grip of addiction and making the journey of recovery. Healthcare professionals, substance use disorder treatment providers, and government agencies need to utilize persons in recovery as a resource. People with lived experience offer an intimate understanding of the nature of addiction, the negative feelings associated with this disease, challenges to be met, and 
whose very presence exemplifies hope for a new life to those still suffering.

Recovery-oriented services include Peer Recovery Support Services (PRSS), Recovery Community Organizations (RCOs), Collegiate Recovery Programs (CRPs) and other supportive community-based organizations. In rural areas where distance to service is a challenge, these recovery support services can be provided through mobile or teleservices. Peer Recovery Support Services provide essential services including help with navigating difficult social and family relationships, and offering employmentrelated advice. These PRSSs often provide a bridge to other communal support systems (mutual aid, faith groups, alcohol and drug-free social and recreational activities) and to other more formal systems such as child welfare offices, healthcare providers, treatment professionals, housing assistance programs, and job training. Recovery Community Organizations provide recovery-oriented education, community outreach, and peer-based recovery services among other invaluable contributions.

To further increase the development of RCOs and enhance their valuable services, Federal agencies should consider uniform standards for recovery support services. These PRSS standards will seek to augment care similar to SAMHSA's Recovery House Guidelines, the National Association of Recovery Residence's (NARR) standards, the Association of Recovery Organizations (ARCO), the Council on Accreditation of Peer Recovery Support Services (CAPRSS), the Oxford House, and other professional organizations with a mission to improve the quality of recovery support services.

Furthermore, while the number of CRPs on the campuses of large public universities, private higher education institutions, and community colleges has increased rapidly over the past decade, they are still the exception rather than the rule. Every higher education campus in America could potentially benefit from some type of CRP. Adolescent recovery support services are especially scarce and of tremendous value to youth, given the importance of peer networks to their social development. Recovery high schools and alternative peer group models hold great promise for meeting the needs of youth, either in active recovery or in encouraging youth to seek it, and we must encourage their increased use across the Nation.

For many individuals seeking recovery, a safe, drug and alcohol-free living environment that encourages recovery is vital to their growth and development. Access to quality recovery housing helps people overcome the challenges associated with substance use disorders.

\section{Improving Opportunities for Employment for Those in Recovery}

Americans in stable recovery from addiction deserve fair consideration for any job for which they are qualified. Today, millions of Americans from all walks of life are in recovery. Many of these individuals have barriers to employment, such as past misdemeanor or felony drug-related criminal convictions that can impede or prevent them from securing employment for which they are fully qualified. In addition to the obstacles created by a past criminal conviction, those in recovery can face additional hardship in finding employment as a result of laws that prohibit the hiring of individuals with a past conviction. These legal restrictions can create additional difficulties for those seeking to fully rejoin the 
community and sustain a life in recovery. The Administration will work across the Federal government and the private sector to increase hiring opportunities for those in recovery, including for those with past criminal convictions. This will include providing the best information to employers on the overall benefits of bringing these individuals back into our workforce, developing best practices to increase their employment prospects, and increasing the availability of workforce training, transportation, and safe housing that enables those in recovery to take their place in the American workforce.

\section{Expanding the Scientific Understanding of Peer Recovery Support Services}

While much is known about the process of addiction and about interventions to help address it, less is known about the recovery process and its various trajectories, components, and stages. A better understanding of the recovery process will help in the design and targeting of both clinical and recovery support service interventions that are stage- and trajectory-specific. Continued research is needed to design and target clinical and recovery support interventions and strategies for long-term recovery. However, while the positive anecdotal evidence of the near-term effectiveness of recovery support service models is strong, empirical and rigorous research is required on their long-term effectiveness, the characteristics of those who benefit most from them, and peer recovery support services' role within and impact on broader systems and communities.

Even though evidence suggests that recovery support service models are efficacious in lessening the consequences associated with active addiction, more rigorous research is required to develop a deeper and broader understanding of how these services can best be utilized to mitigate relapses, save lives, and reach a segment of the population who are in need of services. To date much is known about the process of addiction, including specific interventions and treatment models, but less is known about the recovery process and its various trajectories, components, and stages. A better understanding of the recovery process will help practitioners design interventions that can be more effective in meeting people in all stages of active use and recovery. In other words, more research is needed to design and target clinical and recovery support interventions to assist all people in achieving long-term recovery.

\section{Reducing Stigma and Making Recovery Possible}

Americans in recovery are a vital part of every community in the United States, and they seek the same things other Americans want and need-a good job, a safe place to live, a strong social support network, such as a faith community, and the companionship of neighbors and friends. Many people who go through recovery lack a supportive network and the necessary resources to be successful such as safe housing, transportation, or childcare. These hurdles can impede employment and healing, which can lead to potential relapse. For long-term recovery to work we must create mutually-supportive communities where individuals improve their physical, mental, spiritual, and social well-being and gain skills and resources to sustain their recovery. The millions of Americans in long-term recovery from addiction demonstrate that recovery is possible, and they share the message that while addiction is a chronic disease, it can be effectively addressed with evidence-based treatment. By sharing their 
stories, individuals in recovery help lift the stigma, misunderstanding, and shame that prevent too many Americans from seeking help for substance use disorders. While stigma knows no geographical boundaries, this can be a particular challenge in rural and tribal communities that are often closely knit. By promoting, supporting, and celebrating recovery, we can reduce stigma and offer hope and encouragement to those struggling with addiction. Many people in recovery have also dedicated their lives to helping others affected by substance misuse as recovery coaches and counselors, a critically important and growing component of the addiction service workforce. The Administration will continue in its efforts to better educate the public, healthcare professionals, and policymakers on the science of addiction and the promise of recovery, and how stigma, poor language choice, and misunderstanding can undermine efforts to reduce drug use and its consequences.

\section{Conclusion}

Untreated substance use disorder can result in violence, crime, and risky behavior that jeopardizes the health and safety of individuals, families, and communities. The moment a person is ready and willing to enter treatment can be fleeting and infrequent. In addition to matching the individual with the most appropriate care model, efforts to expand treatment must include the capability to act quickly on the demand for treatment whenever and wherever the opportunity is presented. Anytime someone seeking help for addiction calls a treatment center, doctor's office, hospital, health clinic, or other medical facility, that person should immediately be referred to some level of assistance. Even if a treatment slot is not immediately available, recovery coaches, peer counseling groups, and families who have learned about addiction can provide help until the right treatment opportunity becomes available. It is in everyone's best interest-affected individuals, their families, and the Nation-for high-quality, evidence-based drug treatment to become more easily accessible. The current opioid crisis highlights the urgent need to encourage those who need treatment to seek it, rapidly increase treatment admissions for opioid addiction, improve treatment retention, and increase the number of individuals who successfully achieve sustained recovery. It is also essential to eliminate the stigma, misunderstanding, and legal and regulatory barriers that delay or prevent treatment access and impede recovery. In addition to saving lives and helping people in recovery achieve their full potential, these changes will help ensure that the significant public investment in treatment pays off in terms of long-term recovery.

\section{REDUCING THE AVAILABILITY OF ILLICIT DRUGS IN THE UNITED STATES}

Almost all of the illicit drugs causing American deaths are produced outside the United States and trafficked across the Nation's borders and through the international mail and express consignment carriers. Large and established Drug Trafficking Organizations (DTOs), the Transnational Criminal Organizations (TCOs) responsible for producing and shipping the drugs into the United States, threaten the health and safety of our communities by exposing our citizens to substances such as illicit fentanyl, non-fentanyl synthetic opioids, heroin, cocaine, and methamphetamine, which kill tens of thousands 
of Americans each year. The increased use of illicit drugs burdens the U.S. health care system and leads to lost productivity and civil engagement. Moreover, drug trafficking sustains a vast domestic and international criminal enterprise that enables corruption, undermines governance, has a destabilizing effect on our partner nations, and funds a range of illicit activities. Law enforcement agencies at all levels-Federal, state, local, and tribal-have achieved considerable success in combating drug trafficking and use, yet traffickers continue to refine their methods and adopt new techniques for delivering potent illicit drugs to our communities. Responding to the aggressive trafficking and distribution techniques of DTOs is an urgent national security and law enforcement priority.

The non-medical use of prescription drugs presents another dimension of the availability problem. Many active drug users report obtaining prescription drugs from friends, family members, and in some cases, healthcare providers. The overprescribing of prescription drugs, the diversion of prescription drugs for non-medical use, and the lack of accountability or oversight in prescribing practices increase the availability of prescription drugs in America's homes and workplaces, making it far too easy for them to fall into the wrong hands. Moreover, drug dealers exploit the demand for prescription medicines and traffic in counterfeit pills containing illicit fentanyl, or one of its analogues. These drugs are difficult to distinguish from legitimate prescription medicines, and because they are most often milled and pressed in variable formulations in clandestine locations, it increases the chance for accidental overdose.

\section{Disrupting, Dismantling, and Defeating Drug Traffickers and Their Supply Chains}

While DTOs often are involved in poly-drug trafficking and other criminal activity, the unprecedented rise in deaths from the opioid crisis demands that we prioritize U.S. government efforts on the individuals and groups involved in the smuggling and sale of the most deadly drugs such as synthetic opioids and heroin. As these organizations continue to modify their techniques and operations in an attempt to reduce risk and maximize profit, we must anticipate and then respond to changes in the drug trafficking environment, identify and exploit vulnerabilities in the illicit drug supply chain, and seize the initiative from drug traffickers in order to disrupt their activities and dismantle the infrastructure they use to sustain their illicit enterprise. Along with aggressive actions to prevent the further expansion of these criminal enterprises in our country, we must also work with foreign partners to attack criminal networks, principally those in the Western Hemisphere, whose drug trafficking and associated criminality directly impact migration and border security issues affecting the United States.

\section{Working with International Partners}

The U.S. Government will focus its diplomatic efforts to encourage partner nations to produce results that match the growing threat from illicit drugs. Consistent with the National Security Strategy, we will prioritize assistance with partners who are aligned with U.S. interests, are showing results, and building the capacity to address these threats independent of U.S. assistance programs. This will require partners' renewed commitment to disrupt the illicit supply chain through the interdiction and 
seizure of the illicit drug supply, illicit funds, and weapons; eradicate poppy and coca plants; find and dismantle the labs used for all illicit drug processing; develop and sustain robust law enforcement and justice systems; maintain the rule of law and ferret out corruption; and arrest and prosecute drug traffickers operating within their own land borders, territorial waters, and airspace. These efforts are not only important in their own right but will complement, and be informed by, a strong domestic public health response to the crisis aimed at reducing the use of these drugs in the United States. We will continue to work bilaterally with the primary drug producing and trafficking countries most affecting the United States, emphasizing our shared responsibility for today's drug problems and the strong desire for tangible progress in the years to come. Regional relationships will be an important part of our international approach, allowing us to share information and harmonize our drug policies in the face of a constantly changing threat. Moreover, we will take full advantage of the strong multilateral framework that exists to address the global drug problem, particularly in terms of supporting the three international drug control conventions and providing leadership in the processes for internationally scheduling, controlling, and monitoring illicit drugs and their precursor chemicals.

\section{Combating Illicit Internet Drug Sales}

Over the past three years, illicit drug sales on both the clear and the dark web have further expanded the illicit drug market, allowing individuals to purchase dangerous drugs directly from their manufacturers or individual intermediaries instead of through established trafficking organizations, and have them shipped directly to their homes. We must continue to disrupt the ability of drug traffickers to exploit the anonymity, distance, and financial transaction reliability provided through internet sales by degrading the implicit trust between buyer and seller required for illicit on-line transactions. We must use existing authorities to their maximum effect to target drug traffickers and their enablers by employing both passive and active measures to disrupt and exploit illicit drug related activities operating on both clear and dark webs. Contesting drug marketplaces in the cyber domain and disrupting the use of cryptocurrencies for illicit drug sales requires a coordinated and well-resourced framework of relationships, laws and regulations, procedures, and capabilities. This will allow us to identify and target the network of actors involved, and prosecute those who use the open or dark webs to market, sell, and purchase illicit drugs. Utilizing our full range of authorities and cyberspace capabilities in a sustained effort against the internet drug market, will erode this implicit trust and disrupt illicit operations on the clear and dark webs over time.

\section{Focusing Federal Government Effort against Illicit Drug Delivery through the Mail and Express Consignment Networks}

We must complement our efforts against internet drug sales with a sustained effort to disrupt the flow of illicit drugs shipped through the international mail and express consignment environments. This requires maximizing the policy and regulations, international relationships, facility infrastructure, and technology required to aggressively target, detect, and intercept illicit drugs transported through the international mail and express consignment environments both internationally and domestically. We must work with our international partners to develop the ability to share Advance Electronic Data 
for all international shipments, in accordance with the President's Initiative to Stop Opioid Abuse, and continuously refine targeting algorithms to identify and interdict international shipments before they depart the source country and at U.S. Ports of Entry. We must help critical partner countries develop the ability to detect and intercept illicit drugs in their domestic mail and express consignment systems before those drugs depart for the United States and enter the U.S. mail or commercial carrier system. We must continue our extensive work with private sector partners which is critical to disrupting the manufacturing, marketing, sale, and shipment of drugs through the nation's commercial infrastructure. Finally, we must develop next generation technology and screening capabilities to increase our ability to detect illicit drugs once they enter the mail and express consignment systems within the country, and improve testing capability to determine the precise type and source of illicit drugs seized. This investment in science, technology, resources, and international relationships is necessary to determine the type, source region, production location, and route traveled for all illicit drugs seized by the United States and its international partners.

\section{Interdicting the Flow of Drugs across the Physical Borders and into the United States}

Along with the challenge of drug trafficking via internet sales and mail and express consignment delivery, drugs continue to flow across our land borders and through the maritime and air routes. Stopping these flows must continue to be a part of our comprehensive interdiction efforts. This work includes enhancing the border's physical security infrastructure, especially along our southern border. The historically high levels of cocaine production in Colombia, along with heroin, methamphetamine, and illicit fentanyl production in Mexico, combined with the vast number of routes and conveyances into the United States, make the challenge of combating drug trafficking across our physical borders no less daunting than it has been for the past several decades. Federal agencies should expand efforts in the detection and monitoring of the air and maritime approaches to the United States; the detection of illicit drugs and precursor chemicals shipped in commercial containers; and interdiction of plantbased drugs such as heroin, cocaine, and marijuana, as well as synthetic drugs and their precursor chemicals, along the Nation's land borders. Moreover, increasing cooperation and effort from foreign partners who can contribute vital information on trafficking patterns and assets to seize drugs bound for the United States, will complement U.S. efforts.

\section{Disrupting and Dismantling the Illicit Drug Production Infrastructure}

The United States and Mexico have expanded cooperation to address the common threat of illicit opioids, and both governments agree that reducing the supply of heroin, methamphetamine, and illicit fentanyl is a shared responsibility. Mexico has increased its efforts to eradicate poppy fields more effectively, destroy clandestine laboratories, and interdict heroin and other drugs before they reach the U.S. border. The U.S. Government's partnership with Mexican law enforcement officers, analysts, chemists, and military personnel to identify and safely dismantle clandestine drug laboratories that produce heroin, methamphetamine, and illicit fentanyl has increased Mexico's capability in addressing the dangers synthetic drugs present to law enforcement. 
We must work with partners to address expanding coca cultivation and cocaine production in Colombia and the broader Andean region in a comprehensive manner. Key elements of cooperation with proven partners such as Colombia and Peru include increasing all forms of illicit crop eradication, alternative development and economic opportunities, interdiction, investigation and prosecution, judicial support, and public health cooperation, all of which must be long-term and sustainable. Since coca fields differ in their level of productivity, this approach will be most successful if we focus in areas of high-yield coca cultivation. Unfortunately, these areas generally have limited government services and lingering security concerns, and will require concerted effort over several years to turn the rising tide of cocaine production.

Within the United States, marijuana cultivation on public lands, and within National Forest System lands in particular, is a significant issue. Cultivation activities not only sustain the illicit marijuana trade but also produce large volumes of hazardous materials that pose a significant risk to the public and the environment. Wildlife, soil, and vegetation are often contaminated by the various hazardous substances involved in the cultivation process. Personnel conducting enforcement, cleanup, and regulatory activities, as well as the public, are at considerable health risk from exposure to these chemicals. Continued firm action is required against the exploitation of the Nation's public lands through increased detection, disruption, reclamation, and prosecutions.

The majority of illicit synthetic drugs available in the United States are manufactured abroad. New illicit synthetic drugs and the precursor chemicals used to make them originate predominantly in China, although most of the methamphetamine available in the United States is manufactured in Mexico and the rising production of illicit fentanyl in Mexico has become an increasing concern. Increased collaboration with Mexico, China, and other partners on shared drug priorities can help disrupt drug trafficking networks, along with the corrupt or compromised systems that support them, and reduce the availability of dangerous synthetic drugs in the United States. The United States will continue bilateral exchanges with China, Mexico, Colombia, and other source and transit countries to reduce production and trafficking of synthetic drugs destined for markets in the United States and support collaboration with international partners impacted by drugs from the very same sources.

\section{Leveraging the Full Capabilities of Multi-Agency, Multi-Jurisdictional Task Force Programs}

Transnational drug trafficking organizations, by definition, operate across national, state, and local boundaries to produce, transport, and distribute dangerous and addictive drugs. In order to protect their criminal enterprise, drug trafficking organizations also commit violent crimes, threaten and corrupt public officials, traffic weapons, and launder their criminal proceeds. Accordingly, no single government, or government organization, alone can defeat these threats. Our best strategy to dismantle and disrupt criminal organizations is to employ the coordinated efforts of multi-agency, multi-jurisdiction task forces. Such task forces are best organized to work with international partners and to take coordinated action on shared investigative information and intelligence. 
ONDCP oversees the High Intensity Drug Trafficking Areas (HIDTA) Program which provides assistance to law enforcement agencies operating in areas determined to be critical drug-trafficking regions of the United States. HIDTAs provide an umbrella to coordinate Federal, state, local, and tribal drug law enforcement agencies' investigations, and act as neutral centers to manage, de-conflict, analyze, provide intelligence support to, and execute drug enforcement activities in their respective regions. With the last year's inclusion of Alaska, the first new HIDTA in 17 years, the 29 regional HIDTAs now include designated areas in all 50 states, Puerto Rico, the U.S. Virgin Islands, and the District of Columbia. The regional HIDTAs bring together more than 21,000 Federal, state, local, and tribal personnel from 500 agencies through 800 enforcement, intelligence, and training initiatives, all designed to disrupt illicit drug trafficking and dismantle criminal and drug trafficking organizations. The Administration will ensure strong support for counterdrug enforcement, including by supporting Federal participation in multi-jurisdictional task forces and enhancing support for information sharing at all levels. This will ensure that national data systems receive input from state, local, and tribal agencies, and that these agencies, in turn, have access to data compiled by Federal agencies that can prove vital to their own investigations.

\section{Interrupting the Financial Activities of Drug Traffickers}

Illicit drugs enter the United States from global suppliers as the result of a long and complex process involving manufacture, concealment, movement, purchase, and delivery. The illicit drugs may change hands several times during the process, and this often necessitates the transfer of money, either as payment for services or for delivery of the final product. Traditionally, street-level sales of illegal drugs are conducted with cash, creating immediately liquid assets that are almost impossible to track. As technology and money laundering methods have adapted over the years to circumvent Anti-Money Laundering regulations, drug traffickers have initiated many new techniques to enable the traditional method of hard currency transactions. Although some of these methods create additional investigative evidence, emerging technologies continue to outpace banking regulations and consistently provide drug traffickers the means to launder large amounts of their illicit proceeds.

Most of the revenue generated from illegal drug sales in the United States is maintained at the retail level of drug distribution. However, illicit proceeds that flow back to international sources of drug supply are most often used to finance other illegal activities or the next cycle of illegal drugs flowing into our communities, posing a continual threat to the country. These funds also corrupt and weaken the government infrastructure of source and transit countries, limiting those governments' ability to combat TCOs, escalating violence, and threatening the stability of the governments we partner with to counter illicit activity. We will combat this threat and target the drug proceeds that motivate criminal activity by attacking TCOs' financial capital; preventing the circulation, transfer, and concealment of their illicit proceeds; and, ultimately decreasing their wealth and their incentive to function.

\section{Enhancing Law Enforcement Capacity}

Success in reducing the availability of illicit drugs in our country requires continuing to strengthen 
the capacity and tools to fully understand, and relentlessly respond to, the increased drug threat we face. As our National Security Strategy states, this capacity building includes national-level strategic intelligence and planning capabilities to improve the ability of departments and agencies to work together to combat TCOs, particularly those who traffic drugs at home and abroad. We must improve our capability to dismantle TCOs as a whole through greater coordination and focus, directly benefiting our counterdrug efforts. Improved strategic planning must be informed by better strategic intelligence on transnational organized crime and global criminal networks, fusing law enforcement and Intelligence Community information and intelligence to create the most complete picture available of criminal networks. We must use that information to identify and exploit vulnerabilities in drug trafficking networks, using the full range of law enforcement capabilities including criminal prosecutions, financial disruption tools such as asset forfeiture proceedings, and security operations to remove the profits from crime. Moreover, we must maintain pressure on these organizations over time and prevent them from regenerating their capabilities. We must also emphasize both actions that lead to prosecutions-to reduce networks' ability to operate, through the investigation, arrest, and prosecution of critical personnel -and those that lead to the long-term disruption of network operations such as the seizures of illicit drugs, precursor chemicals, illicit funds, and weapons.

Our conventional focus on targeting high-level individuals within the hierarchy of well-organized and sophisticated DTOs mustevolvetoward identifying and targeting vulnerable critical components of more fluid and dynamic organizations such as financial facilitators, corrupt officials, and key transporters, to affect a significant disruption of DTO activities, targeting key nodes to attack the entire network through its enablers. Degrading and defeating criminal networks that have become more resilient because they are decentralized, redundant in capabilities and capacities, and compartmentalized, requires identifying the key nodes enabling DTO operations and simultaneously targeting them for maximum effectiveness over time. Agile interagency and international coordination will allow for better detection of changes in the trafficking supply chain, which will support intelligence-driven operations against identified vulnerabilities, from drug production to delivery to the end user.

\section{Conclusion}

The increased availability and use of illicit drugs is taking far too many American lives and destroying American families. It burdens the U.S. health care system and leads to lost productivity and civil engagement here at home, and global drug trafficking sustains a vast domestic and international criminal enterprise that enables corruption and destabilizes partner nations abroad. America's drug crisis has created a complex national security, law enforcement, and public health challenge for the Nation, and this challenge will remain with us for the foreseeable future. We must leverage the full capabilities of the U.S. intelligence and law enforcement communities, our military, domestic law enforcement and criminal justice capabilities, and sustained engagements with the governments of key partner nations and international organizations to stop the flow of these drugs across our borders and into our communities, and use that capability to posture ourselves for an ever-evolving drug trafficking environment. Our actions will continue disrupting the evolving illicit supply chain, decreasing the 
volume of drugs being sold over the internet; decreasing the cultivation of illicit crops like poppy and coca as well as the volume of illicit drugs being produced for export to the United States; increasing the amount of illicit drugs seized before entering the United States; increasing the amount of forfeited assets; increasing the number of convictions for drug-related crimes; and increasing the pace of review of, and imposition of international controls on, emerging dangerous substances.

Achieving the President's outcome of reducing the number of Americans losing their lives to drug addiction in today's crisis, and preparing now to dominate the drug environment of the future, requires deliberate actions focused on clear priorities and tangible outcomes to reduce the availability of drugs in our Nation. However, lasting success requires those actions to complement, and be informed by, a strong domestic public health response to reduce the use of these drugs in the United States which makes possible enormous profits for drug traffickers and fuels the illicit drug market. Bold and decisive national security, law enforcement, and public health efforts are needed to lift the Nation from the shadow of drug use and move toward the President's goal of a stronger, healthier, and drugfree society today and in the years to come.

\section{GOALS AND BUDGET PROJECTIONS}

While this Strategy focuses on aggregate progress toward a strategic outcome rather than enumerating all of the tasks and activities that organizations at the Federal, State, local and Tribal levels must undertake in order to stem the tide of America's drug crisis, it is nonetheless important to establish objectives that align to the Strategy's nine goals for achieving the overarching strategic outcome of saving American lives and building a healthier, drug-free society. This not only ensures the necessary policies, priorities, and objectives of drug control agencies and interagency partners are adequately aligned and resourced to advance the President's drug control priorities, but also serves to identify those areas where a refinement of the Strategy may be necessary to close an identified gap, or areas where a shift in specific agency focus or resources can attain greater effects in achieving the President's overarching strategic objective.

\section{Goals for Reducing Illicit Drug Use, Objectives, and Targets for Measuring Progress}

This Strategy's three lines of effort: preventing drug use before it starts, providing treatment leading to long-term recovery for those suffering from substance use disorder, and reducing the availability of drugs in the United States, will be advanced by the accomplishment of the nine goals listed below. Each goal directly supports the three lines of effort and contains one or more quantifiable and measurable objectives. The Strategy, with its three lines of effort, describes in detail how the aggregate progress across the interagency directly contributes to the achievement of the nine goals. Assessing the sustained progress toward achieving those objectives, and realizing the related goals, is enabled by annual targets that will be continually assessed over a five year period. ${ }^{3}$

${ }^{3}$ The accompanying Performance and Reporting System contains each of the annual targets for each Objective and a detailed description of how each was determined. 
A description of how each goal and its supporting objective(s) was determined, including the data, research, or other information used to inform the determination to establish them, is discussed in the National Drug Control Strategy: Performance Reporting System. The baseline for all objectives is 2017, the first year of the Administration, except for three objectives for which the earliest data is for either 2018 or 2019. Development of the goals and objectives was an iterative process conducted by review of the latest research and data and consultation with subject matter experts within ONDCP and from the relevant National Drug Control Program Agencies.

- Goal 1: The number of Americans dying from a drug overdose is significantly reduced within five years.

- Objective 1: Overdose deaths are reduced by reaching annual targets in percentage reductions each year, and by a total of 15 percent by 2022 .

- Goal 2: Educate the public, especially adolescents, about drug use, specifically opioids.

- Objective 1: Reduce the rate of past year use of any illicit drug among youth each year, and by 15 percent by 2022 .

O Objective 2: Reduce the rate of past year use of opioids among youth each year, and by 15 percent by 2022 .

- Goal 3: Evidence-based addiction treatment, including MAT for opioid addiction, is more accessible nationwide.

- Objective 1: Increase the percentage of specialty treatment facilities providing Medication-Assisted Treatment for opioid use disorder every year, so that 100 percent do so by 2022.

- Objective 2: Increase the percentage of Federal health care workers certified to administer, prescribe, and dispense buprenorphine for opioid use disorder every year, and to 10 percent by 2022 .

- Goal 4: Increase mandatory prescriber education and continuing training on best practices and current clinical guidelines.

- Objective 1: Increase the percentage of Federal prescribers that have completed continuing education on best practices and current clinical guidelines in prescribing opioid medications every year, and by 50 percent by 2022 .

- Goal 5: Reduce nationwide opioid prescription fills.

- Objective 1: By increasing education and adherence to proper prescribing practices for effective pain management, reduce nationwide opioid prescription fills every year, and by 33 percent by 2020 and maintain that reduction in 2021 and 2022. 
- Goal 6: Increase Prescription Drug Monitoring Program interoperability and usage across the country.

- Objective 1: Increase the number of states integrating electronic health records with their Prescription Drug Monitoring Programs every year, and to 30 by 2022.

- Goal 7: Significantly reduce the availability of illicit drugs in the United States by preventing their production outside the United States.

- Objective 1: Reduce potential production of cocaine (pure metric tons) in Colombia every year, and by 42 percent by 2022 .

- Objective 2: Reduce potential production of heroin (pure metric tons) in Mexico every year, and by 25 percent by 2022 .

- Goal 8: Significantly reduce the availability of illicit drugs in the United States by disrupting their sale on the internet, and stopping their flow into the country through the mail and express courier environments, and across our borders.

- Objective 1: Increase the amount of cocaine removals (in metric tons) in the transit zone every year, and by 10 percent by 2022 .

- Objective 2: Increase the amount of seizures (in metric tons or kilograms) at the U.S. southern border every year, and by 10 percent by 2022 for each of the following drugs: cocaine, fentanyl, heroin, and methamphetamines.

- Objective 3: Increase the number of online drug vendor investigations every year, and by 20 percent by 2022 .

- Goal 9: Illicit drugs are less available in the United States as reflected in increased price and decreased purity as measured by price per pure gram.

- Objective 1: Increase the average price per pure gram of cocaine every year, and reach $\$ 250$ by 2022 .

- Objective 2: Increase the average price per pure gram of heroin every year, and reach $\$ 1,400$ by 2022 .

- Objective 3: Increase the average price per pure gram of methamphetamine to $\$ 120$ by 2022 .

- Objective 4: Increase the cost of illicit fentanyl (purity not known) charged by dealers per kilogram to customers every year, and by 10 percent to $\$ 3,300$ by 2022 . 


\section{Projections for National Drug Control Program and Budget Priorities}

The 2019 Strategy set policy goals and objectives for the Nation, along with associated performance measures and targets to achieve those goals and objectives. ONDCP considers the Strategy's projections for policy priorities to be the budget priorities because they indicate to the National Drug Control Program Agencies what the Administration's long-term priorities are, and those agencies are expected to provide resources for those priorities over the course of the Administration. ONDCP's funding guidance also establishes the budget priorities-for the current and future years-for National Drug Control Program agencies to meet the performance targets and achieve the policy goals and objectives of the Strategy.

\section{Budget and Performance Summary}

The FY2020 Budget and Performance Summary, published in May 2019, can be found at:

https://www.whitehouse.gov/wp-content/uploads/2019/05/FY-2020-Budget-and-Performance.pdf

ONDCP will release the National Drug Control Strategy: FY 2021 Budget and Performance Summary (Budget Summary) after the President's proposed budget is released in early 2020. The Budget Summary contains information on the President's FY 2021 drug control budget, as well as the enacted and actual funding levels for FY 2020 and FY 2019, by National Drug Control Program Agency (NDCPA) and subordinate elements, as well as historical funding levels by function. Appendices contain information on the resources to support the National Drug Control Strategy Border Strategies and the National Treatment Plan. In addition, the Budget Summary provides a description of each agency's mission, program descriptions, and significant changes in the FY 2021 request compared to the FY 2020 enacted or continuing resolution amount. The FY 2021 Budget Summary also contains details of each agency's program performance metrics and a section on the assessment of the contribution of each NDCPA to achieving the goals and objectives of the Strategy. 


\section{Appendix 1: List of Supporting Planning Documents}

The National Drug Control Strategy has six supporting plans or documents that address specific requirements necessary for achieving the Strategy's overarching strategic outcome and the nine goals, objectives, and targets used to assess performance. Taken together, the base Strategy and its six supporting plans and documents compose the Administration's National Drug Control Strategy:

- National Drug Control Strategy: National Treatment Plan-articulates how the Federal Departments and Agencies and their key stakeholders at the State, local, Tribal, and private sectors of society will expand treatment for substance use disorders.

- National Drug Control Strategy: Southwest Border Counternarcotic Strategy-articulates the Government's strategy for preventing the illegal trafficking of drugs across the international border between the United States and Mexico, including through ports of entry and between ports of entry on the border.

- National Drug Control Strategy: Northern Border Counternarcotic Strategy-articulates the Government's strategy for preventing the illegal trafficking of drugs across the international border between the United States and Canada, including through ports of entry and between ports of entry on the border.

- National Drug Control Strategy: Budget and Performance Summary Report-presents the details of the President's resource requirements to implement the Strategy and to inform Congress and the public about the total amount proposed to be spent on all supply reduction, demand reduction, State, local, and tribal affairs, including any drug law enforcement, and other drug control activities by the Federal Government. There are 16 Federal Departments and Agencies that have been designated by the ONDCP Director as Drug Control Program Agencies. Budget detail is provided at the program, project, and activity levels (the level at which the Office of Management and Budget and the agencies request funding and Congress appropriates it). The report also provides detail on agency-level performance metrics to enable assessment of progress toward achieving programmatic objectives.

- National Drug Control Strategy: Performance Reporting System-describes the Strategy's goals, objectives, and annual targets established for reducing drug use, availability, and the consequences of drug use.

- National Drug Control Strategy: Data Supplement-provides the data that enables an assessment of current drug use and availability, impact of illicit drug use, and treatment availability. The more than 150 data tables provide national, state, local, and international data on drug use; attitudes and perceptions toward drug use; drug-induced morbidity and mortality; drug treatment; drug-related crime, including drugged driving; drug price and purity; cultivation and/or the production of drugs; and drug eradication and seizures. 


\section{Appendix 2: ONDCP's Role in Facilitating the Achievement of the Strategic Goals and the Coordination Mechanisms Necessary for Achieving the Strategic Goals}

ONDCP's Role: Established by the Anti-Drug Abuse Act of 1988, and reauthorized by the SUPPORT for Patients and Communities Act (Public Law 115-271), ONDCP leads, coordinates, and oversees the implementation of the national drug control policy, including this Strategy. There are numerous facilitation mechanisms that the Director of the National Drug Control Policy uses to achieve the nine goals and objectives of this Strategy, the most important of which are the two National Coordination Groups within ONDCP and the specific functional coordinators discussed below. In addition, the Director, in conjunction with ONDCP's Office of Performance and Budget, conducts a yearly evaluation of the effectiveness of this Strategy in light of the activities and accomplishments of the National Drug Control Program Agencies.

\section{Existing Coordination Mechanisms:}

National Cocaine Coordination Group (NCCG): Responsible for guiding and synchronizing interagency efforts to reduce the availability of cocaine. The NCCG identifies gaps and redundancies in Federal government's efforts to address the cocaine problem set and works to solve them in order to achieve its goal of reducing the number of fatal overdoses. The NCCG works with the National Security Council (NSC), Domestic Policy Council (DPC), and other White House elements, as appropriate, on issues involving counternarcotics, Colombia, Peru, transnational organized crime, and the implementation of the 2019 National Drug Control Strategy.

National Opioids and Synthetics Coordination Group (NOSCG): The focal point for guiding and synchronizing interagency efforts to reduce the availability of all illicit or illegally trafficked opioids, plant-based and synthetic, as well as psychostimulants such as methamphetamine. To achieve its primary measure of effectiveness, reducing the number of fatal overdoses, the NOSCG identifies gaps and redundancies in the Federal government's efforts to address the opioid and synthetics problem set and works to close them.

To do so, the NOSCG coordinates widely across the interagency and with partners in the private sector and the state-level and below, starting with ten engagements per month in direct support of the implementation of its Heroin Availability Reduction Plan. These engagements include a weekly TS-SCI video teleconference (VTC) with all Intelligence Community partners; a monthly VTC with US Embassy Mexico to align and coordinate counternarcotics and security activities and issues; a monthly VTC with US Embassy Beijing to coordinate and align policy issues related to synthetic opioids; a monthly Federal law enforcement Secure VTC to share information on emerging trends; a monthly nationwide webinar with 20 partner states in all four US census regions that brings together law enforcement and public health officials to share trends, best practices, and lessons learned; and a monthly teleconference to allow forensic scientists, medical examiners, coroners, intelligence analysts, and members of the law enforcement community to share trend data and information on newly identified substances seized by 


\section{U.S. Customs and Border Protection (CBP).}

The NOSCG also co-chairs or supports NSC-led sub-policy coordinating committees, policy coordinating committees, and deputies committee meetings as appropriate on issues involving counternarcotics, Mexico, China, illicit finance, transnational organized crime, and special interest topics such as the Community Response to Drug Overdose and the safe handling of illicit fentanyl for first responders. Along with the DPC, the NOSCG co-chairs meetings on public health-related topics such as prescription drug monitoring programs, safe prescribing, naloxone availability and use, and increasing the availability of MAT for opioid use disorder. The NOSCG also organizes, leads, or participates in White House stakeholder events on specific topics for private sector partners such as private sector cooperation on stemming the flow of synthetic opioids and counterfeit prescription drugs into the United States, and overdose response and Naloxone availability in colleges and universities. Finally, the NOSCG supports both the NSC and DPC to co-chair meetings on implementation of the 2019 Strategy, providing subject matter and policy expertise on those strategy objectives related to opioids, illicit opioids, synthetic drugs, dark web drug sales, and illicit finance.

Demand Reduction Coordinator and Public Health, Education and Treatment Task Force (PHET): The Demand Reduction Coordinator leads ONDCP's Public Health, Education, and Treatment Task Force which establishes the ONDCP response to the Nation's addiction crisis, and provides strategic guidance to lead the interagency effort to plan, coordinate, and manage the public health responsibilities of the President's Strategy. The task force portfolio includes primary drug prevention, public education on the consequences of drug use, removing barriers to access effective addiction treatment including medication assisted therapies, criminal justice diversion programs, and establishing recovery support programs. Collaboration and coordination with other Federal agencies, State, local and Tribal health officials, and health policy-related interest groups is key to the development and implementation of these demand reduction functions.

United States Interdiction Coordinator (USIC): Responsible for establishing the Federal government's interdiction strategy and assessing the sufficiency of assets committed to illicit drug interdiction. To accomplish this, the USIC staff works across four primary lines of effort: border strategy development, information sharing, interdiction capability and capacity development and support, and interagency coordination. The USIC publishes the Administration's National Interdiction Command Control Plan (NICCP) and multiple border strategies in support of the of the President's Strategy. To develop and implement these availability reduction functions, the USIC collaborates with White House peers, international partners, Federal, State, local, and Tribal law enforcement officials, and the HIDTAs.

State, Local, and Tribal Affairs Coordinator (SLTAC): Coordinates drug control efforts between Federal agencies and State, local, and Tribal governments. The SLTAC meets with State, local, and Tribal governments to hear their concerns and coordinate their drug control efforts with the drug control efforts of the Federal agencies. This helps to ensure cooperation and information sharing, and to avoid duplication between Federal efforts and State, local, and Tribal efforts. The SLTAC also ensures that State, local, and Tribal governments commit to and take steps to achieve the Strategy's goals. 
Emerging Drug Threats Coordinator: Chairs the Emerging Threats Committee that is responsible for recommending to the Director the criteria for declaring or terminating an emerging or evolving drug threat in the United States, monitoring, discussing, and identifying an evolving and emerging drug threat in the United States, and recommending to the Director when such a declaration or termination needs to be made. In the case of a declaration, the Chairperson and the Committee are responsible for developing, coordinating, and overseeing the execution of a Response Plan to address the drug threat as outlined in 21 USC §1708: Emerging Threats Committee, plan, and media campaign.

Performance Budget Coordinator: Responsible for ensuring the Director has sufficient information necessary to analyze the performance of each National Drug Control program Agency, the impact Federal funding has had on the goals in the Strategy, and the likely contributions to the goals of the Strategy based on funding levels of each National Drug Control Program Agency, to make an independent assessment of the budget request of each agency; and advising the Director on agency budgets, performance measures and targets, and additional data and research needed to make informed policy decisions. 


\section{Appendix 3: Mission Statement and List of National Drug Control Program Agencies and How They Help Achieve the Strategic Goals}

The National Drug Control Program's mission is to develop policies and to coordinate, promote, and implement initiatives that result in a stronger, healthier, drug-free society today and in the years to come. This mission is implemented through a series of congressionally mandated activities set forth in the agency's authorizing legislation, as well as through strategic initiatives aimed at preventing the initiation of illicit drug use, providing treatment services leading to long-term recovery for those suffering from addiction, and aggressively reducing the availability of illicit drugs in American communities.

The National Drug Control Program Agencies are the Departments of Agriculture, Defense, Education, Health and Human Services, Homeland Security, Housing and Urban Development, Interior, Justice, Labor, State, Transportation, Treasury, and Veterans Affairs, the Federal Judiciary, the Office of National Drug Control Policy, the United States Postal Inspection Service, and the Court Services and Offender Supervision Agency for the District of Columbia.

ONDCP has a performance evaluation plan for the nine goals of the Strategy that includes performance measures for each National Drug Control Program Agency, to the extent practicable, sets performance targets for those measures, and presents an estimate of the Federal funding needed to achieve performance targets and objectives. The Strategy establishes the long-range goals for reducing illicit drug use and the consequences of illicit drug use. The performance measures and targets that support the policy objectives of the Strategy are described in the National Drug Control Strategy: Performance Reporting System (PRS). ONDCP collaborates with National Drug Control Program Agencies to align their activities that support implementing the Strategy's policy objectives to the PRS performance targets. ONDCP also collaborates with agencies to establish agency-specific performance measures and targets to assist ONDCP and the agencies in evaluating their contributions to achieving Strategy goals. This agency-specific performance data is presented in the Performance section of the National Drug Control Strategy: Budget and Performance Summary (Budget Summary). The budget request for the agency, also presented in the Budget Summary, describes the resources needed to meet the agency's performance targets, and ensures their contribution to achieving the performance goals and objectives of the Strategy. ONDCP's construct for performance evaluation planning allows it to assess the government's effectiveness in achieving policy objectives by aligning agency funding and performance to the strategic goals and policy priorities of the Strategy.

For a more in-depth description of the role of each NDCPA, their related programs, assets and activities to achieve Strategy goals, please refer to the FY 2020 Budget and Performance Summary that was published in May 2019, and to the FY 2021 Budget and Performance Summary that will be published after the President's proposed Budget is released. 


\section{Appendix 4: Role of Key Stakeholders and Partners in the Strategy}

ONDCP, established by the Anti-Drug Abuse Act of 1988, and reauthorized by the SUPPORT for Patients and Communities Act (Public Law 115-271), is required to consult a wide array of experts, key stakeholders, and officials while developing the President's National Drug Control Strategy. It requires the ONDCP Director to work with the heads of the National Drug Control Program agencies; ONDCP's internal coordinators; the Interdiction Committee and the Emerging Threats Committee; appropriate Congressional Committees; State, local and Tribal officials; private citizens and organizations with experience and expertise in demand and supply reduction; and appropriate representatives of foreign governments. ONDCP met this requirement by soliciting the views of the following individuals and organizations during the development of the National Drug Control Strategy as detailed below.

\section{Consultation with National Drug-Control Program Agencies (21 USC $\$ 1705($ b)(4)(A)(i))}

ONDCP works closely with agencies that have been charged to oversee drug prevention, treatment and recovery, and availability reduction. Input was solicited from fifteen Federal Departments, Independent Agencies, and the Federal Judiciary. ONDCP works regularly throughout the interagency (including the NSC and the DPC) to ensure the effective coordination of drug programs. These agencies, based on their unique mission, roles, functions, will play key roles in achieving all nine goals contained in the strategy

\section{Consultation with ONDCP coordinators (21 USC \$1705(b)(4)(A)(ii))}

The various coordinators within ONDCP (the Performance Budget Coordinator, the Interdiction Coordinator, the Emerging and Continuing Threats Coordinator, the State, Local, and Tribal Affairs Coordinator, and the Demand Reduction Coordinator) are each an integral part of the development of the Administration's policy and budget priorities in the areas of prevention, treatment and recovery, and reducing the availability of illicit drugs. Each coordinator contributed to the development of the Strategy and will play key roles in achieving the nine goals.

\section{Consultation with Interdiction and Emerging Threats committees (21 USC § 1705(b)(4)(A)(iii))}

ONDCP serves a leadership role on both the Interdiction Committee (TIC) and the Emerging Threats Committee, and engaged both groups to gather their views on the Strategy. The TIC works to enhance and expand cooperation and coordination with all agencies engaged across the operational spectrum of supply reduction and interdiction. Similarly, the new Emerging Threats Committee has established the criteria for declaring or terminating an evolving or emerging drug threat, and it is monitoring the landscape to identify such threats in the United States. Both Committees' perspectives were essential when considering both the public health and public safety aspects of the Strategy. The Interdiction Committee will have a significant role in achieving Goals 1, 7, 8, and 9 of the Strategy. The Emerging Threats Committee has members from the Prevention, Treatment and Recovery, and the Interdiction (law enforcement) communities, they will play key roles across the three lines of effort and with each of the nine goals. 


\section{Consultation with appropriate Congressional committees (21 USC $\$ 1705(b)(4)(A)(i v))$}

The Administration works closely with the Congress in the development, implementation, oversight, and funding of the National Drug Control Strategy. ONDCP requested input from over 250 members of the House and Senate who sit on the House Oversight and Reform, Judiciary, Energy and Commerce, and Appropriations Committees, as well as the Senate Drug Caucus, Judiciary, Health, Education, Labor and Pensions and Appropriations Committees. Their input, as well as the continued interaction between Administration and Congress, was critical to the development of this Strategy.

\section{Consultation with State, local, and Tribal officials (21 USC $\$ 1705(b)(4)(A)(v))$}

ONDCP meets, interacts and consults regularly with State, local and Tribal officials when implementing the Strategy. Governors from all states and territories, regional commissions, Tribal leaders, local prevention experts, and public health and public safety officials (including those at the HIDTAs) were asked to provide input in the areas of prevention, treatment, and availability reduction. These views are important because they offer insight into local drug policy issues as well as potential solutions. These communities draw from key stakeholders in the Prevention, Treatment and Recovery, and Reducing the Availability of Illicit Drugs arenas, so they will have an important role in achieving all nine goals.

\section{Consultation with private citizens and organizations (21 USC \$1705(b)(4)(A)(vi and vii))}

ONDCP solicited input from a comprehensive array of nonprofit organizations, governmental associations, medical associations, health plans and issuers, drug policy stakeholders, community anti-drug coalitions, professional associations, research and educational institutions, and faith-based organizations representing the interest of both the supply-side and demand reduction communities. These citizens and organizations span all three lines of effort and will, therefore, have significant responsibility for achieving all nine objectives.

\section{Consultation with foreign governments (21 USC \$ 1705(b)(4)(A)(viii))}

ONDCP and the interagency works regularly with the international community to confront transnational criminal organizations, reduce illicit production, and protect citizens and democratic institutions from corruption or subversion. ONDCP requested input from both a number of partner nations as well as global and regional organizations including the United Nations Office on Drugs and Crime and the International Narcotics Control Board. Foreign governments are involved in preventing initiates to drug use, providing treatment services to move people into long-term recovery, and for interdicting the flow of drug into their countries and around the globe. This strategy will rely on the expertise and capabilities of our foreign partners across the three lines of effort and the related nine goals.

Review of Stakeholders' Drug Control Activities and Their Role in Achieving the Strategic Goals (21 USC $\S$ $\underline{1705(C)(1)(E) \text { and }(F)(i i))}$

ONDCP routinely examines how international, state, local, tribal, and the private sectors' activities align with the strategy to facilitate a coordinated and effective drug control system at all levels of government. 
We do that through the strategy consultation process, in the annual performance review of the strategy, and in ongoing community outreach. The Strategy is not intended to enumerate every activity the Federal government and key stakeholder must execute in order to achieve our common vision, but it articulates a common way forward for stakeholders in academic, civic, government, law enforcement, and public health communities at the Federal, state, local, and tribal level to take collective action to address the crisis challenging communities across America. It is only through a united and unified effort in which the Federal government works with, and in support of, creative and resourceful individuals and organizations across the country and with our international partners, that we can address this complex national security, law enforcement, and public health problem.

Regarding stakeholders' consultation, as noted in the introduction of the Strategy, ONDCP relied heavily on the expertise of the stakeholders discussed above during the consultation and development phases of the Strategy. Their input was decisive in determining the nine goals as well as the underlying activities we must accomplish in order to achieve the strategic outcome of building a stronger, healthier, drug-free society and reducing the number of Americans losing their lives to drug addiction. More information regarding how stakeholder input helped to inform the strategy's goals can be found in the Performance Reporting System.

Stakeholders and their activities are also important in implementing the goals of the Strategy. The following bullets outlines major groups of stakeholders and include a sampling of their current activities and their role in facilitating the achievement of the Strategy's goals:

- Prevention Organizations: Prevention organizations engage in a variety of activities and programs to prevent people, especially young people, from initiating drug use. Some focus on education in schools, while others are more broadly community-based. These prevention organizations will play an important role in implementing the prevention line of effort and Strategy Goals 1,2 , and 5. For example, the stakeholders can help achieve the strategic goals through early recognition and addressing risky substance use which can help interrupt the trajectory towards more chronic substance use disorders. They would also do so through increasing the quantity and quality of prevention education, and in particular by making such prevention programs evidence-based.

- Public Health, Treatment, and Recovery Organizations: Public health, treatment and recovery organizations provide drug treatment to those with addictions, ensure sustainable recovery for those in recovery from addictions, and address broader public health concerns such as conditions associated with drug use. These public health, treatment, and recovery organizations will play an important role in implementing the treatment and recovery line of effort and Strategy Goals $1,3,4$, and 5. For example, they would do so through increasing the quantity and quality of addiction treatment and recovery programs, and in particular by making such treatment and recovery programs evidence-based. Once an individual is in recovery, stakeholders can help achieve the strategic goals by creating mutually-supportive communities where the individual can improve their physical, mental, spiritual, and social well-being and gains skills and resources 
to sustain their recovery.

- Law Enforcement Organizations: Law enforcement organizations stop drug trafficking through targeting drug trafficking organizations and reducing availability of drugs, and can assist with public health efforts through the criminal justice system as well. These law enforcement organizations will play an important role in implementing the Availability Reduction line of effort and Strategy Goals 1, 8, and 9. For example, these are numerous activities conducted by National Drug Control Program Agencies that enhance and coordinate domestic law enforcement efforts leading to reduced drug-related violence and property crime as well as substance use and availability. Law enforcement action would result in the further disruption of the evolving illicit drug supply chain and increase the amount of drugs seized before entering the United States.

- State, Local and Tribal Governments: State, local, and tribal governments play roles on both the public health and law enforcement aspects of the Strategy, and they are key partners of ONDCP and Federal agencies in all aspects of drug control. They often organize and fund various public health, prevention, and treatment efforts for drugs. They also run state, local, and tribal law enforcement agencies, which is where the majority of national drug prosecutions occur. State, local and tribal governments will play an important role in implementing all of the Strategy's lines of effort and goals. It is only through a unified effort in which the Federal government works with, and in support of, the creative and resourceful individuals at the State, Local, and Tribal level of government that we can successfully address this complex national security, law enforcement, and public health problem.

- International Organizations and Foreign Governments: International organizations and foreign governments play a role in working with U.S. agencies and law enforcement in particular to reduce source country production of drugs and interdict traffickers. International organizations and foreign governments will play an important role in implementing primarily the Availability Reduction line of effort and Strategy Goals 1, 7, and 9. For example, National Drug Control Program agencies conduct activities to reduce illicit drug availability by assisting our international partners in managing the consequences of drug production; trafficking; consumption in their own societies, including training and equipping security forces; raising awareness of sciencebased practices and programs to prevent, treat and recover from substance use disorder; and supporting economic development programs primarily intended to reduce the production and trafficking of illicit drugs. By taking advantage of the strong multilateral framework that exists to address the global drug problem, particularly in terms of supporting the three drug control conventions and providing leadership in the processes for internationally scheduling, controlling, and monitoring illicit drugs and their precursor chemicals, we will continue to advance the strategic goals. 


\section{Appendix 5: National Drug Control Strategy Research and Data Collection Plan}

Scope \& Criteria for Policy Questions: While there are a range of data collection and research activities germane to the implementation of the National Drug Control Strategy, this data research plan focuses its policy questions on the identification and analysis of emerging or increasing trends that may require significant shifts in strategy, approach, or resource allocation to identify if we are postured to deal with these drug trends. This initial plan does not provide programmatic details outlining our progress.

As per the requirements of 21 U.S.C. $\S 1705(c)(1)(M)$, this plan also:

- Identifies data required to answer each question;

- Explains how data will be collected, analyzed and applied;

- Describes data collection and analysis challenges, such as data availability, data timeliness and integrity, and data sharing constraints; and,

- Details the steps ONDCP and drug control agencies will take to implement the plan.

\section{Research Plan Policy Question (RPPQ) 1:}

- Question: What new or emerging drugs or significant shifts in U.S. illicit drug use patterns may require changes in law enforcement or public health strategies, resource allocation or national strategy or priorities?

- Do these trends include significant shifts in primary drug of choice, prevalence, route of administration, forms of poly drug use, overdose, use-related co-morbidities and mortality, or other consequences?

- Are there trends that require an emergency or alternative response at the national, regional, state, or local levels?

This information would give senior policymakers the latest illicit drug use patterns, including emerging drugs to enable early detection and a rapid public health and public safety response to, ultimately, reduce morbidity and mortality.

- Data or Datasets: Current data systems such as the National Survey on Drug Use and Health (NSDUH), the Healthcare Cost and Utilization Project (HCUP), and the National Emergency Medical Services Information System (NEMSIS) provide information on the latest illicit drug use trends for the most commonly used substances.

NSDUH surveys a statistical sample of Americans living in households about their alcohol and other drug use and their mental health status, but does not collect adequate information on the use of emerging drugs. Administrative hospital billing records from HCUP can provide data on inpatient stays and emergency department visits related to non-fatal drug overdoses, based on 
physician diagnoses and International Classification of Diseases, 10 Revision, Clinical Modification (ICD-10-CM) codes, but may not be corroborated with toxicology testing. NEMSIS provides data from Emergency Medical Service patient records resulting from an emergency 911 call, including non-fatal drug overdoses, however a toxicological test result is usually not included in the record. Postmortem testing can currently measure new or changing patterns of drug use.

- Methods or Analytical Approach: The U.S. Government can monitor emerging drugs by testing individuals at high risk-such as probationers, emergency-room patients, and the drug treatment population-for their drug use to get a better warning of new drugs of abuse. To achieve this testing, the US Government should establish a sentinel warning system-a system that actively monitors high-risk drug using populations-that conducts urinalysis tests on a broad panel of substances beyond those most commonly encountered. For example, the Community Drug Early Warning System (CDEWS) study was a pilot for such a sentinel system. CDEWS retested previously collected urine samples from populations very likely to use drugs. Results revealed that these highrisk populations commonly used multiple drugs that would not be detected using a traditional toxicology panel. Finally, systematic monitoring of online drug fora like Bluelight, Reddit, and Erowid via an artificial intelligence data mining interface may shed light on the substances current drug users are seeking out and purchasing.

- Challenges or Deficiencies: Existing data systems, such as NSDUH, HCUP, or NEMSIS are constrained by their design to report on drugs that are already commonly used and provide little or no insight into emerging drugs or use patterns. While postmortem testing can currently measure new or changing patterns of drug use, variations in local toxicological forensic testing and delays in national standardization and reporting limit its use as an early detection capability. Enhanced frontline surveillance systems could be further developed to identify emerging national and local drugs and trends, subject to the availability of funding.

\section{RPPQ 2:}

- Question: Are significant shifts occurring in the domestic illicit production of synthetic drugs and other emerging substances?

This information will provide senior policymakers an understanding of the latest domestic drug production threat.

- Data or Datasets: The National Seizure System (NSS) collects domestic data on illicit drug and laboratory seizures.

- Methods or Analytical Approach: The DEA's Signature Programs, which determines the likely source country of a small sample of heroin and cocaine seizures, could potentially help identify domestic production. CBP palynologists have successfully used pollen testing to identify the geographic origin of seized fentanyl and related substances. Analysis of pollen and other residual organic matter have enabled palynologists to identify provinces in China where fentanyl has been 
packaged, and shows promise for better identifying the source country of synthetic drugs. This method could be further tested to determine if it could be applied to domestic pollen to determine if a drug was produced in the United States. The U.S. Government also monitors domestic laboratory seizures of illicit synthetic drugs as an indicator of domestic production. For example, estimated levels of domestic methamphetamine production are assumed to be low because numbers of domestic laboratory seizures are few. Forensic analysis-the collection, analysis, and reporting of information critical to investigations by law enforcement-can also provide insight into domestic production trends.

- Challenges or Deficiencies: While the U.S. Government has some domestic production statistics, real-time surveillance of domestic production is limited. Also, due to the United States' negligible drug production, it is not among the countries for whom a source signature has been established. Source country signature analysis is not possible for synthetic drugs in the same fashion as plantbased drugs, like heroin and cocaine. DEA's labs and signature programs could test a greater proportion of seized drug material for content, purity, and source country signature. CBP's palynology department could be expanded to geo-locate the packaging source location of a greater proportion of seized synthetic drugs. In tandem, consistent law enforcement resources need to be applied toward regular monitoring for and detection of domestic clandestine drug labs.

\section{RPPQ 3:}

- Question: Are criminal actors exploiting new vectors (e.g., transshipment locations, methods of smuggling) for U.S. bound illicit substances?

Senior policymakers need this information to ensure activities are prioritized toward the greatest concealment threats.

- Data or Datasets: Existing law enforcement seizure databases can provide some insight into current vectors of illicit substances. However, information about drug trafficking trends and common concealment methods are typically derived from targeted and time-limited intelligence gathering and law enforcement operations. For example, the El Paso Intelligence Center (EPIC) provides tactical intelligence to Federal, state, and local law enforcement agencies on a national scale-at times identifying new concealment methods in its intelligence reports.

- Methods or Analytical Approach: Policymaker understanding of the drug trafficking and use environment is essentially based upon three things; an in-depth understanding of the environment as it is, valid and necessary assumptions about how it will change over time, and a collective understanding about how actions can be taken to shape that environment in order to achieve the strategy's long-term goal, in this case to reduce the number of Americans dying from drug use. To do this policymakers rely upon a large body of reporting and datasets that each have unique capabilities and limitations. Law enforcement seizure data provides insight into the types of drugs seized during law enforcement operations within the United States, their value, and their purity. Seizure data from ports of entry identify the volume and variety of drugs seized as traffickers attempt 
to bring them into the United States. Chemical signature and profiling data tells us the geographic origin of plant-based drugs or the chemical composition of synthetic drugs, and crop estimate data provides the magnitude of plant-based drug production in other countries that produce drugs for the US market. Similarly, public health data provides us insight in the size, behaviors, preferences, and usage patterns among the drug using population, as well as longitudinal trends in drug us across the country over time. Moreover, public health information is used to identify many of the consequences of drug use for individuals, families, and communities. Although each of these individual data sources have known limitations, taken together they can provide the most complete available understanding of drug availability and use in the United States. More importantly, they allow policymakers to identify changes in that environment to identify whether or not the strategy's assumptions remain valid, and to see if there are gaps in our Federal government capability that need to be filled through regulatory, legislative, or resource changes.

- Challenges or Deficiencies: Whether law enforcement agencies activities are normative, generalizable, or scalable is difficult to judge absent consolidated law enforcement databases establishing baseline trends. Policymakers also have difficulty judging what front-end resources (e.g., detection technologies, person-power, screening levels) are most impactful against these new event types. Considerable ongoing interagency collaboration would be required to establish incoming and outgoing vector baseline thresholds, the operational and process requirements and maintenance of a consolidated data system, and the most effective use of detection technologies. Significant and efforts in technology, law enforcement operational capacity, big database architecture, and randomized data collection and analysis would be required to improve detection capabilities for new and under-resourced vectors, develop a consolidated data system that is useful both operationally and for policymakers, and establish baselines for specific locations and concealment methods.

\section{RPPQ 4:}

- Question: How well does substance use disorder treatment capacity (e.g., opioid treatment programs, residential treatment facilities, office-based opioid treatment, and outpatient specialty treatment) respond to new or emerging shifts in drug use within the United States?

- Is a shift in resource allocation required to better respond to needs?

Senior policymakers need this information to determine if there is sufficient treatment support and to ensure that resources are appropriately targeted as domestic drug use shifts.

- Data or Datasets: Current surveys such as the NSDUH and the Monitoring the Future (MTF) provide information on the latest illicit drug use trends for the most commonly used substances for adults and youth. The Treatment Episode Data Set (TEDS) provides demographic and substance use characteristics of admissions to treatment for abuse of alcohol or drugs, while the National Survey of Substance Abuse Treatment Services (N-SSATS) collects data on the location, scope, and characteristics of substance abuse treatment facilities throughout the United States. 
- Methods or Analytical Approach: Compare use and treatment admission data at the state, regional, and local levels to available treatment capacity to identify potential discrepancies between treatment availability and need.

- Challenges or Deficiencies: There is no data source that provides real-time available treatment capacity that can be cross-referenced against drug trends in demand.

\section{Director's Next Steps:}

The Director will establish an Interagency Drug Research Group composed of individuals from the National Drug Control Program Agencies chaired by ONDCP to effectuate the data collection plan and help explore data needs from future policy questions related to the National Drug Control Strategy. 